\title{
Macroalgae transplant to detect the occurrence of anthropogenic nutrients in seawater of highly tourist beaches in Mediterranean islands
}

\author{
Geraldina Signa $^{1,2}$, Cristina Andolina ${ }^{1,2 *}$, Antonio Mazzola ${ }^{1,2}$, Salvatrice Vizzini ${ }^{1,2}$ \\ 'DiSTeM, Dipartimento di Scienze della Terra e del Mare, Università degli Studi di Palermo, via Archirafi 18, \\ 90123 Palermo, Italy \\ ${ }^{2}$ CoNISMa, Consorzio Nazionale Interuniversitario per le Scienze del Mare, Piazzale Flaminio 9, 00196 Rome, Italy \\ *Corresponding author e-mail: cristina.andolina01@unipa.it
}

Received: 26 June 2020 / Accepted: 1 August 2020

\begin{abstract}
In the Mediterranean region, islands are among the most important tourist destinations, being sites of considerable naturalistic, historical and cultural importance. This is highly beneficial for local economies, but may also represent a threat for the environment, especially during the peak season (i.e. summer). Indeed, the sharp demographic increase concentrated in a relatively short period may negatively affect the quality of coastal marine systems and the provision of ecosystem services, producing in turn negative feedbacks on tourism industry. Nevertheless, the assessment of the environmental impact of tourism on coastal seawater has been seldom addressed. Here, we show the results of the biomonitoring approach adopted in the tourist Island of Rhodes (Greece), in the context of the Interreg Med BLUEISLANDS project. The study involved short-term macroalgae transplantation and incubation, and, through the analysis of nitrogen stable isotopes, provided a time-integrated picture of the occurrence of anthropogenic nutrients, which are indicators of water quality and might be missed by routine water quality monitoring programs. Main findings ruled out a marked input of anthropogenic nutrients potentially threatening the functioning of coastal ecosystems and highlighted overall good environmental conditions. In addition, this approach provided spatial data useful to produce GIS maps, useful tools that may help the decisional process of policy-makers, for adopting management practices to mitigate the environmental impact and foster sustainable tourism.
\end{abstract}

Keywords: seaweed, Cystoseira, biomonitoring, stable isotope, mapping, tourism, anthropic impact

\section{Introduction}

Since the 1950s, tourism has increased considerably up to the present day along Mediterranean coasts, with positive social and economic repercussions, but intensifying negative side effects on the natural environment. Marine and coastal tourism is certainly an important component of the development of many countries worldwide, as well as the major foreign exchange earner (UNWTO, 2019). At the same time, the increasing popularity of tourism exerts a great pressure on the coasts, which are already highly subjected to other anthropic pressures due to urbanization and industrial settlements, fishing and agriculture (Hall, 2001). The majority of the ecological problems associated with tourism and adjoining recreation activities arises from excessive visitor numbers heavily concentrated during the summer months within restricted areas (Davenport and Davenport, 2006). The development of the HORECA sector (e.g. beach hotels and resorts, restaurants, refreshment stands, beach-bars, night-clubs) coupled with the overcrowding of beaches and the plethora of recreation and leisure beach activities (e.g. bathing and swimming, sport fishing, scuba diving, windsurfing, jet-skiing, yachting and high speed shipping) place a significant stress upon the 
beaches and the adjoining coastal areas. Recently, a strong relationship between touristic activities and the provision of ecosystem services in the Mediterranean coastal areas has been pointed out by Drius et al. (2019). The authors found that nutrient cycling may be altered by excess nutrient input into coastal areas, influencing, in turn, the ecosystem services. In particular, nutrient input from point sources (e.g. wastewater treatment plants, tourist infrastructure and spots) due to poor runoff control, malfunctioning and/ or overflow of undersized treatment plants, may change the natural nutrient loading pattern of coastal seawater, lowering water quality and threatening the functioning of the adjacent marine habitats (Abaya et al., 2018). In turn, lowering of water quality in terms of water turbidity, harmful algal blooms and low fish abundance, triggers a negative feedback on the tourist sector itself, as it causes a reduction of cultural services provision and a loss of the amenity value of the coastal areas (e.g. fewer recreational opportunities) (Keeler et al., 2012).

Although the potential harmful impact of increasing tourism on the marine environment is a well-known fact, studies focusing on the relationship between tourism and its associated environmental impact are scant (Anderson et al., 2015; Bellan and Bellan-Santini, 2001; Gössling, 2002; Mwaura et al., 2017). Moreover, the European bathing water legislation (Bathing Water Directive 2006/7/EC), since 1975 , is primarily based on microbial indicators. Nutrient enrichment, when evaluated, is addressed through the analysis of nutrient concentration and/or phytoplankton biomass, according to the standard monitoring programs (WFD 2000/60/EC, 2000).

A good opportunity to investigate the relationship between Mediterranean coastal tourism and anthropogenic nutrient enrichment was provided by the Interreg Med BLUEISLANDS project (https:// blueislands.interreg-med. $\mathrm{eu} /$ ), whose main aim was to identify, address and mitigate the effects of the seasonal variation of waste generated in Mediterranean islands due to tourism. In this context, a monitoring system was set up in Mediterranean islands to evaluate the effect of tourist peak on seawater quality, in terms of anthropogenic nutrient enrichment, using a time-integrated manipulative approach based on biomonitoring techniques with transplanted macroalgae.

Active biomonitoring using transplanting techniques is based on the relocation of animal/vegetal bioindicators in selected areas at different environmental conditions, to assess changes of different features (e.g. chemical, biochemical, physiological, etc.) over an incubation period. This technique has been successfully applied worldwide to address the impact of anthropic activities on coastal areas, focusing mainly on inorganic and organic contamination (e.g. Signa et al., 2015) and nutrient enrichment (e.g. Costanzo et al., 2001; Dailer et al., 2010; Deutsch and Voss, 2006; Gröcke et al., 2017). In particular, macroalgae transplantation is deemed a useful tool for environmental monitoring and management of areas affected by sewage treatment plants outflow (Costanzo et al., 2005, 2001; Dailer et al., 2010), industrial effluents (Alquezar et al., 2013), agricultural runoff (Deutsch and Voss, 2006) and fish farm activities (García-Sanz et al., 2011). This is because macroalgae are reliable indicators of nutrient enrichment in aquatic ecosystems as they assimilate biologically available nutrients dissolved in the water column and have a high nutrient turnover (i.e. from days to weeks), hence responding rapidly to change in environmental conditions (Fernandes et al., 2012; García-Seoane et al., 2018). In this context, the analysis of nitrogen stable isotopes in macroalgae gives reliable information about the origin of nutrients to which they are exposed to, for several reasons. Dissolved inorganic nitrogen of marine and anthropic origin differs in its isotopic signature, varying, indeed, from 0 to $4 \%$ and from 7 to $38 \%$ respectively (Dailer et al., 2010 and references therein). Showing low or no fractionation during nitrogen uptake (Deutsch and Voss, 2006; Gartner et al., 2002), macroalgae reliably mirror the $\delta^{15} \mathrm{~N}$ value of local dissolved inorganic nitrogen, giving space- and time-integrated information about pulsed nutrient loadings in coastal seawater (Costanzo et al., 2005; Huntington and Boyer, 2008; Rossi et al., 2018).

Here, we show the results of a study carried out to detect the occurrence of anthropogenic nutrients in coastal seawaters through a methodological approach based on the analysis of spatial patterns in $\delta^{15} \mathrm{~N}$ of transplanted macroalgae. The study was carried out in summer 2019 in the tourist Island of Rhodes (Greece) within the Interreg Med BLUEISLANDS project. By repeating the same experiment in the same sites as in 2018 (see Signa et al., 2020), we had the opportunity to explore whether, under similar tourist pressure, the results were consistent at an interannual scale, and to further test the methodological approach.

\section{Study area}

The Island of Rhodes (Greece) was selected because of the high density of tourist numbers, activities and infrastructures over a rather restricted area. The island is part of the Dodecanese Archipelago, in the south-eastern part of the Aegean Sea close to Turkish coasts, and is one of the most famous tourist destinations in Greece and the whole Mediterranean basin (Tselentis et al., 2006). After the second half of the past century, tourism became the most productive sector in the island, and, since the beginning of the present century, more than one million tourists and nine million overnights occur in the island every year, peaking in very recent years (Pappas, 2008). The northeastern side of the island is characterized by the highest tourist con- 
centration (Kyriakou et al., 2017; Tselentis et al., 2006). In particular, the Faliraki area, which was pristine until the 70 's, was subjected to a rapid land-use conversion in the 80 's, by the building of many beach resorts and the development of a new settlement in order to cover all the needs of mass tourism (Economou, 2007). A recent carrying capacity analysis revealed that the northeastern area of the island is fully saturated because of the excess number of tourists (Kyriakou et al., 2017; Tselentis et al., 2006).

\section{Materials and methods}

\subsection{Experimental approach and field activities}

The monitoring campaign was carried out during the summer tourist peak (i.e. August) of 2019 in the same sites and using the same methodological approach based on a short-term macroalgae transplantation and incubation, as by Signa et al. (2020). Three experimental sites were chosen along the Rhodes eastern coasts, having similar environmental conditions (e.g. depth, exposition, water circu- lation and sediment type), but a different tourist pressure (i.e., presence of tourist infrastructures and activities along the beaches), aiming at comparing a high tourist site with two control sites. In more detail, the eastern coast of Rhodes is interested by the southern branch of the Asia Minor Current that flows toward south-west (Theocharis et al., 1999). The popular beach of Faliraki, which is featured by many large tourist infrastructures (i.e. seaside resorts) on the beachfront, and restaurants, bars and tourist shops at the back of the beach, was chosen as Tourist site. In contrast, the beaches of Traganou and Afandou, where only small lidos are attended mainly by locals, were selected as Control sites (hereafter Control 1 and Control 2) (Fig. 1).

Whole thalli of the brown macroalga Cystoseira compressa (Esper) Gerloff \& Nizamuddin, 1975 (order Fucales) were collected from the rocky shores of Ladiko (hereafter Collection site), known as an unpolluted site on the eastern side of Rhodes and characterized by high abundance of the selected species (Tsiamis et al., 2007, Tsiamis personal communication). In particular, five thalli of $C$. compressa were collected for recording the $\delta^{15} \mathrm{~N}$ signature before the transplanting (Day 0 - baseline), and other five thalli were

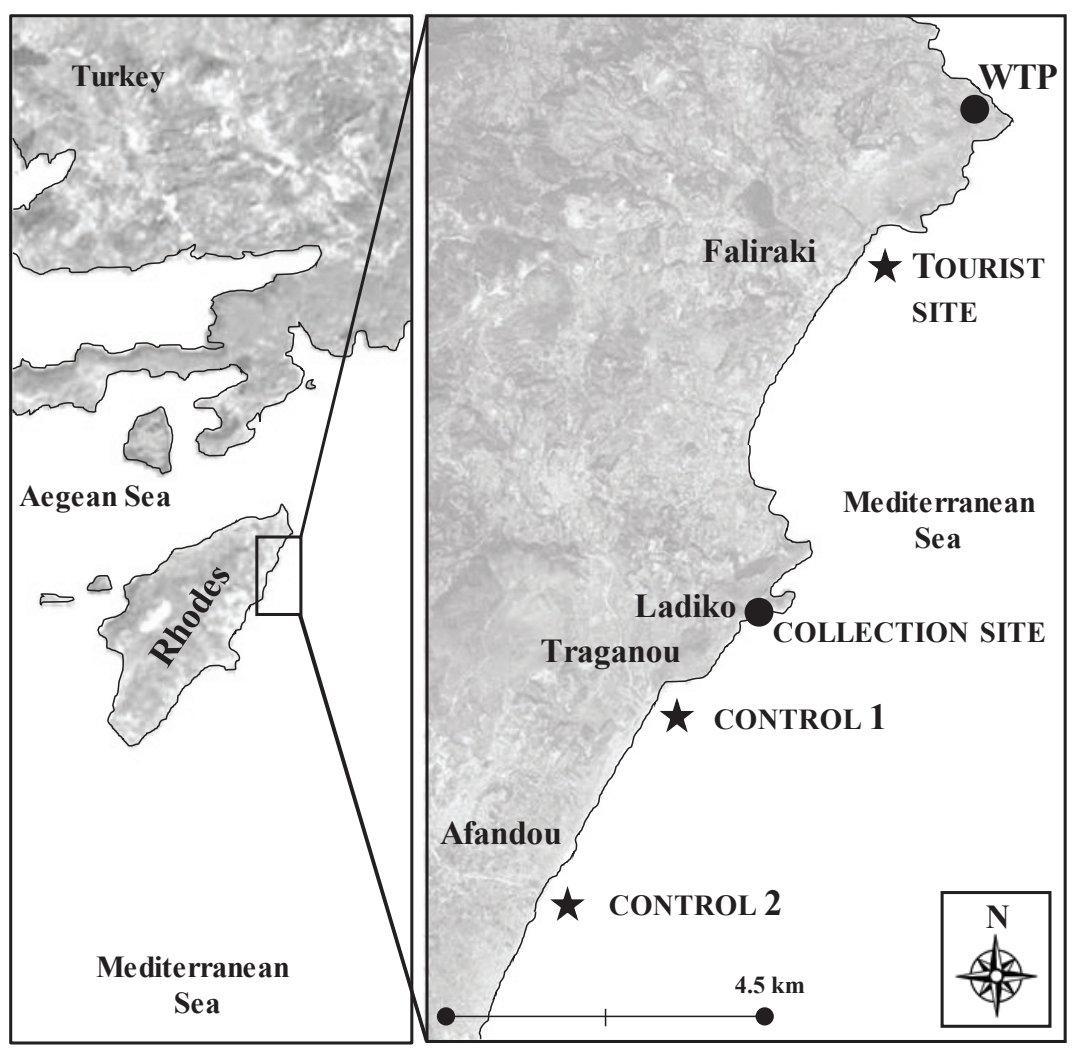

Fig. 1. Study sites in Rhodes: the experimental sites (Tourist site, Control 1 and Control 2) are indicated with a star, while the collection site and the wastewater treatment plant (WTP) are indicated with a circle. 
collected to be incubated in situ within the same devices and for the same duration as the experimental transplant (see below) to evaluate the effect of the experimental procedure on macroalgae $\delta^{15} \mathrm{~N}$ (in situ control). Additional 72 thalli were individually transplanted and incubated within removable devices in 30 and $42(21+21)$ georeferenced points, respectively at the Tourist site and both Control sites, distributed along three transects parallel to and distant from the coastline respectively 100 (T1), 200 (T2) and $300 \mathrm{~m}$ (T2). In more detail, 12, 10 and 8 transplant points, distant $50 \mathrm{~m}$ each other, were set along the three transects T1, T2 and T3 at the Tourist site at a depth of $5.7 \pm 0.7 \mathrm{~m}, 5.8 \pm 1.0 \mathrm{~m}$ and $6.4 \pm 1.0 \mathrm{~m}$ respectively, and, similarly, 8, 7 and 6 transplant points were set at Control 1 at a depth of $6.5 \pm 0.1 \mathrm{~m}, 8.4 \pm 0.3 \mathrm{~m}$ and $10.0 \pm 1.7 \mathrm{~m}$ respectively in and at Control 2 at a depth of $3.6 \pm 0.1 \mathrm{~m}$, $5.2 \pm 0.1 \mathrm{~m}$ and $7.1 \pm 1.0 \mathrm{~m}$ respectively (Fig. 2a). The incubation devices were made of nylon net bags, which were anchored to the bottom and kept at a depth of $1.5 \mathrm{~m}$ below the surface with a buoy, to ensure good light conditions and limit any interference with bathing and boating activities (Fig. 2b). The incubation lasted 3 full days, as a short duration is deemed a good tradeoff that ensures macroalgae to record changes in $\delta^{15} \mathrm{~N}$, before detrimental factors, such as siltation and biofouling, might affect the algal response (Costanzo et al., 2005; Huntington and Boyer, 2008). At the end of the 3-day incubation, all the devices were collected, the macroalgae were stored in the cold and then frozen at $-20^{\circ} \mathrm{C}$ upon arrival at the laboratory. Similarly, after three days, the incubation devices were collected in the in situ control, while five additional thalli naturally occurring at the collection site were collected to record the $\delta^{15} \mathrm{~N}$ signature after 3 days (Day 3 ).

Moreover, seawater temperature and salinity were measured using a multiparameter probe (Hanna Instruments HI98194), and surface seawater was collected in triplicate $(10 \mathrm{~L}$ each) to record the background nitrogen isotopic signature and nitrogen concentration in the suspended particulate organic matter (SPOM), proxy respectively for nitrogen origin and concentration in seawater (Cole et al., 2005; Signa et al., 2012). Additionally, water collected from the last tank of the wastewater treatment process of the Wastewater Treatment Plant (WTP) of Rhodes (Fig. 1) was collected in triplicate (2 L each) to be analysed for the $\delta^{15} \mathrm{~N}$ value and the total nitrogen content.

\subsection{Laboratory activities and data elaboration}

In the laboratory, the apical tip of each macroalga frond was selected for subsequent processing and isotopic analysis. Indeed, having the species an apical growth, apical tips record short-term isotopic values and concentration of seawater nutrients (Viana and Bode, 2013). Apical tips were cut, rinsed with distilled water and scraped with a scalpel to remove epiphytes, when needed. Seawater samples were prefiltered at $200 \mu \mathrm{m}$, and then filtered on precombusted $\left(450{ }^{\circ} \mathrm{C}, 4 \mathrm{~h}\right)$ filters $(\mathrm{GF} / \mathrm{F}$ Whatman, pore size $0.45 \mu \mathrm{m})$ to select the particulate fraction. Macroalgae apices and SPOM filters were then oven dried at $60{ }^{\circ} \mathrm{C}$ for 48 hours and subsequently ground to a fine powder using a micromill. An aliquot (2-3 $\mathrm{mg}$ ) of each powdered sample was packed into tin capsules and analysed for $\delta^{15} \mathrm{~N}$ and $\mathrm{N} \%$ using an Isotope Ratio Mass Spectrometer (Thermo Delta IRMS Plus XP) coupled to an Elemental Analyser (Thermo Flash EA1112). Nitrogen stable isotope ratio was expressed in $\delta$ unit notation, as parts per mil deviation from the international standard (atmospheric $\mathrm{N}_{2}$ ) as follows:

$$
\delta^{15} \mathrm{~N}=\left[\left({ }^{15} \mathrm{~N} /{ }^{14} \mathrm{~N}_{\text {sample }}\right) /\left({ }^{15} \mathrm{~N} /{ }^{14} \mathrm{~N}_{\text {standard }}\right)-1\right] \times 10^{3} \text {. }
$$

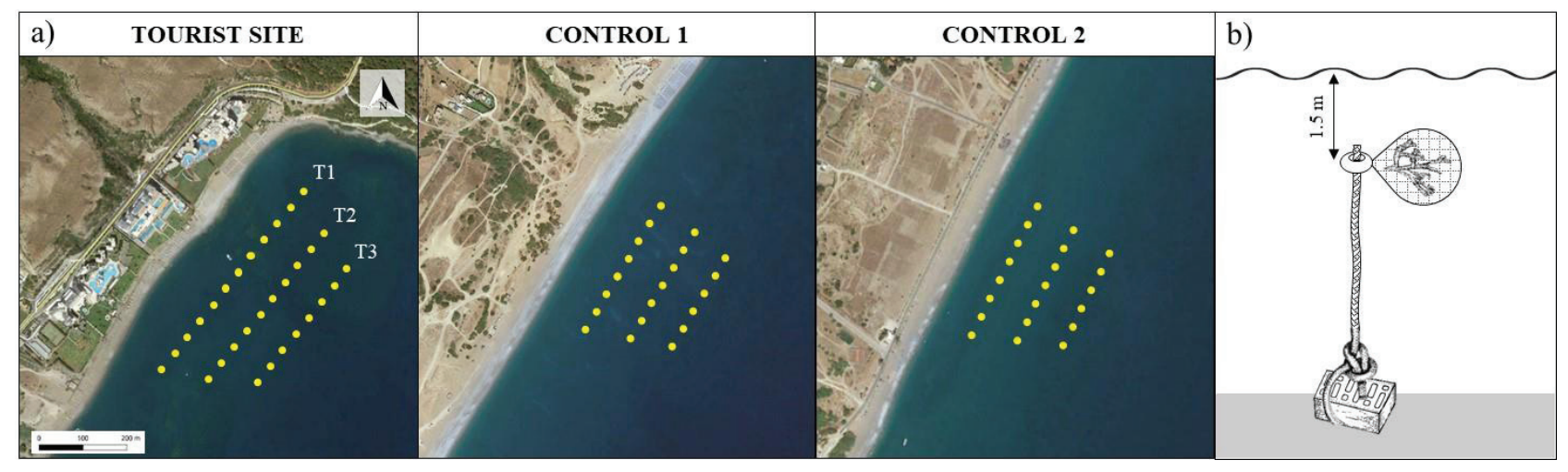

Fig. 2. a) Experimental fields at Tourist and Control sites. The yellow dots represent the transplant points where macroalgae were incubated across the three transects at different distance from the coastline (T1 - $100 \mathrm{~m}$; T2 - $200 \mathrm{~m}, \mathrm{~T} 3-300 \mathrm{~m})$. b) Scheme of a transplant device. 
Analytical precision based on the standard deviation of replicates of internal standards (International Atomic Energy Agency IAEA-NO-3) was 0.2\%o."

Univariate permutational analysis of variance (PERMANOVA - PRIMER 6 v6.1.10 \& PERMANOVA+ $\beta 20)$ based on Euclidean distance matrices obtained from untransformed data was run for testing for differences:

i) between years and sites in $\delta^{15} \mathrm{~N}$ values and total nitrogen content of the suspended particulate organic matter (SPOM) through a design with two fixed and orthogonal factors: Year (2 levels: 2018 and 2019) and Site (5 levels: Collection site, Tourist site, Control 1, Control 2, WTP);

ii) among collection days in the $\delta^{15} \mathrm{~N}$ signature of the macroalgae $C$. compressa collected at the Collection site in August 2019 through a design with one fixed factor: Collection day (3 levels: Day 0, Day 3 and in situ control);

iii) between years, sites and transects in the variation of the $\delta^{15} \mathrm{~N}$ signature $\left(\Delta \delta^{15} \mathrm{~N}\right.$ - see below) of the macroalgae $C$. compressa after the incubation through a design with three fixed and orthogonal factors: Year (2 levels: 2018 and 2019), Site (3 levels: Tourist site, Control 1, Control 2) and Transect (3 levels: T1, T2, T3).

Data of the 2018 campaign were taken from Signa et al. (2020).

A t-test between independent groups (STATISTICA v.10) was run separately for each site and transect to compare the isotopic values of the macroalgae transplanted in the 2019 campaign, with the correspondent baseline, namely the mean $\delta^{15} \mathrm{~N}$ value of the macroalgae collected in the Collection site at Day 0. The Levene test was previously run to check the homogeneity of variance.
The effect of the incubation in the Tourist and Control sites on the isotopic values of the macroalgae was assessed by taking into account the difference between the $\delta^{15} \mathrm{~N}$ of the macroalgae retrieved at the end of the incubation period and the correspondent baseline, expressed as $\Delta \delta^{15} \mathrm{~N}$. Afterwards, the analysis of the $\Delta \delta^{15} \mathrm{~N}$ spatial patterns in the 2019 monitoring campaign was run using the Inverse distance weighted (IDW) interpolation technique in Quantum GIS (V. 2.18.7) (Philip and Watson, 1982; Watson and Philip, 1985), as has already been done for the 2018 campaign by Signa et al. (2020). Based on available literature about the isotopic response of Cystoseira spp. (García-Sanz et al., 2011; Orlandi et al., 2014), $\Delta \delta^{15} \mathrm{~N}$ values were categorised into 4 classes indicating isotopic depletion (green contours, $\Delta \delta^{15} \mathrm{~N}<0 \%$ ), and low (light pink contours, $\Delta \delta^{15} \mathrm{~N}$ : 0-0.5\%), moderate (dark pink contours, $\Delta \delta^{15} \mathrm{~N}$ : $0.5-1 \%$ ) or high (red contours, $\Delta \delta^{15} \mathrm{~N}$ : $>1 \%$ ) isotopic enrichment.

\section{Results}

In this section, we report the results of the 2019 monitoring campaign and we compare them with those of the 2018 campaign (Signa et al., 2020). Seawater temperature and salinity recorded during the experiment were comparable across the experimental (Tourist site, Control 1 and Control 2) and collection sites of Rhodes. In more detail, seawater mean temperature and salinity were respectively $29.1 \pm 0.3{ }^{\circ} \mathrm{C}$ and $39.3 \pm 0.3 \mathrm{psu}$ across sites, showing lower values than those recorded in August 2018 (Table 1).

Both $\delta^{15} \mathrm{~N}$ and total nitrogen content in suspended particulate organic matter (SPOM) showed comparable values across years and sites (Fig. 3) with the exception of the

Table 1. Mean and standard deviation of temperature and salinity in the study sites of the Island of Rhodes in August 2018 and 2019. Data of the 2018 campaign were taken from Signa et al. (2020).

\begin{tabular}{|c|c|c|c|c|}
\hline \multirow[t]{2}{*}{ Temperature $\left({ }^{\circ} \mathrm{C}\right)$} & \multicolumn{2}{|c|}{2018} & \multicolumn{2}{|c|}{2019} \\
\hline & mean & s.d. & mean & s.d. \\
\hline Collection site & 29.7 & 0.4 & 29.1 & 0.4 \\
\hline Tourist site & 30.2 & 0.6 & 29.0 & 0.6 \\
\hline Control 1 & 30.7 & 0.8 & 29.1 & 0.1 \\
\hline Control 2 & 30.5 & 1.2 & 29.2 & 0.1 \\
\hline \multirow[t]{2}{*}{ Salinity (psu) } & \multicolumn{2}{|c|}{2018} & \multicolumn{2}{|c|}{2019} \\
\hline & mean & s.d. & mean & s.d. \\
\hline Collection site & 41.0 & 0.4 & 38.9 & 0.5 \\
\hline Tourist site & 41.4 & 0.6 & 39.2 & 0.4 \\
\hline Control 1 & 41.2 & 0.8 & 39.6 & 0.2 \\
\hline Control 2 & 41.6 & 1.2 & 39.3 & 0.1 \\
\hline
\end{tabular}


Wastewater Treatment Plant (WTP), where $\delta^{15} \mathrm{~N}$ and total nitrogen content were significantly higher than in the other sites (Table 2).

Mean $\delta^{15} \mathrm{~N}$ of Cystoseira compressa at the Collection site in 2019 varied from $2.5 \pm 0.2 \%$ at Day 0 to $2.1 \pm 0.3 \%$ and $2.1 \pm 0.4 \%$ at Day 3 and the in situ control respectively with no significant differences (PERMANOVA, MS $=0.34$, Pseudo- $\mathrm{F}_{(2,12)}=3.33$, p-value $\left.=0.07\right)$ among days of collection. This indicates that the experimental procedure (e.g. cut, handling, incubation) did not affect the isotopic

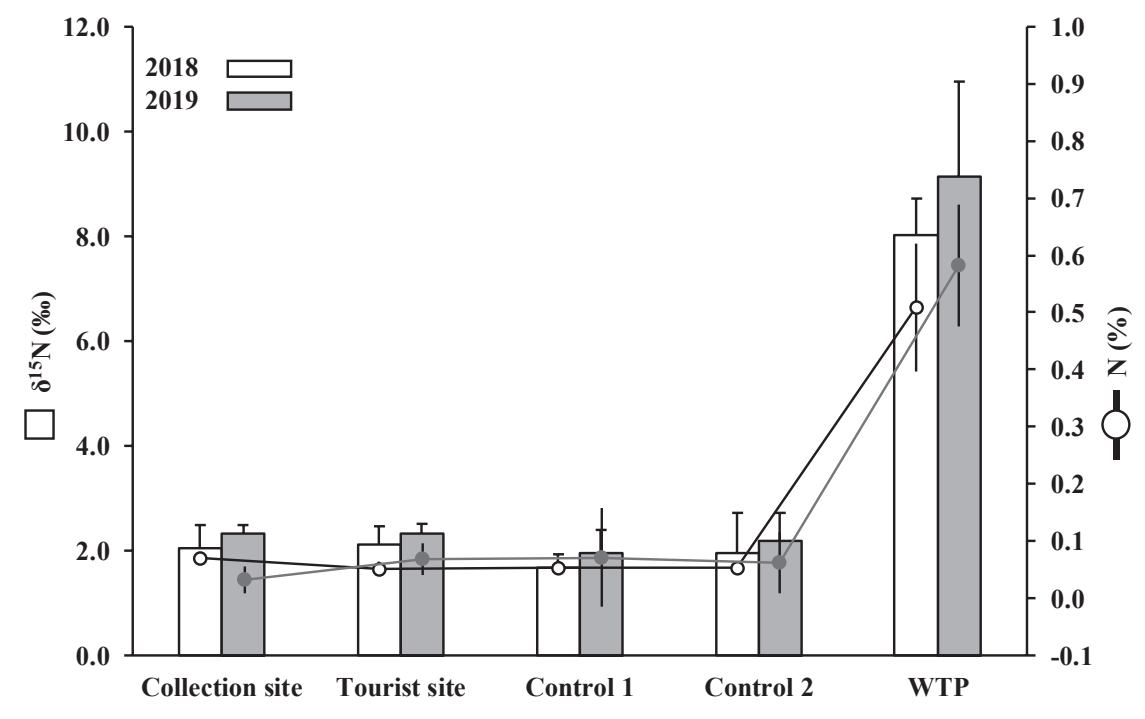

Fig. 3. Mean ( \pm standard deviation $) \delta^{15} \mathrm{~N}$ and total $\mathrm{N}$ content in suspended particulate organic matter (SPOM) from the study sites and the wastewater treatment plant (WTP) at Rhodes in August 2018 and 2019. Data of the 2018 campaign were taken from Signa et al. (2020).

Table 2. Results of PERMANOVA (main test and pairwise tests) testing the differences between $\delta^{15} \mathrm{~N}$ values and nitrogen content of suspended particulate organic matter (SPOM) collected in the study sites and the wastewater treatment plant in August 2018 and 2019. CS: Collection site; TS: Tourist site; C1: Control 1; C2: Control 2; WTP: wastewater treatment plant. Data of the 2018 campaign were taken from Signa et al. (2020).

\begin{tabular}{|c|c|c|c|c|c|c|c|}
\hline $\begin{array}{l}\text { PERMANOVA } \\
\text { Main test }\end{array}$ & $\begin{array}{c}\text { Source } \\
\text { of variation }\end{array}$ & df & MS & Pseudo-F & $\mathbf{P}($ perm $)$ & Perms & Pair-wise tests \\
\hline \multirow{4}{*}{ a) $\delta^{15} \mathrm{~N}(\% 0)$} & Year & 1 & 1.37 & 2.60 & 0.110 & 997 & \multirow{4}{*}{$\mathrm{WTP}>\mathrm{CS}=\mathrm{TS}=\mathrm{C} 1=\mathrm{C} 2$} \\
\hline & Site & 4 & 56.85 & 107.75 & 0.001 & 998 & \\
\hline & Year x Site & 4 & 0.26 & 0.49 & 0.764 & 999 & \\
\hline & Residuals & 21 & 0.53 & & & & \\
\hline \multirow{4}{*}{ b) $\mathbf{N}(\%)$} & Year & 1 & 0.01 & 1.84 & 0.206 & 997 & \multirow{4}{*}{$\mathrm{WTP}>\mathrm{CS}=\mathrm{TS}=\mathrm{C} 1=\mathrm{C} 2$} \\
\hline & Site & 4 & 0.15 & 28.52 & 0.001 & 996 & \\
\hline & Year x Site & 4 & 0.02 & 3.48 & 0.072 & 999 & \\
\hline & Residuals & 21 & 0.01 & & & & \\
\hline
\end{tabular}


composition (Day 3 vs. in situ control) and that no isotopic variation naturally occurred across the 3 days of the experiment (Day 0 vs. Day 3).

Macroalgae incubated in the experimental sites in August 2019 showed slightly lower values than the baseline (i.e. the macroalgae collected at the Collection site at Day 0) (t-test p-value < 0.05) (Fig. 4). This was not observed in 2018 (Signa et al., 2020), when most values were over- lapped to the baseline and only the macroalgae incubated in the closest transect to the shoreline (T1) at the Tourist site were slightly more ${ }^{15} \mathrm{~N}$-enriched than the baseline (Fig. 4). Accordingly, the isotopic variation $\left(\Delta \delta^{15} \mathrm{~N}\right)$ of the incubated macroalgae showed a significant decrease in 2019 (from -2.0 to $0.4 \%$ ), higher than that recorded in 2018 (from -0.9 to $0.7 \%$ ) (Tab. 3, Fig. 4). Hence, the georeferenced maps of $\Delta \delta^{15} \mathrm{~N}$ showed that the vast ma-

Table 3. Results of PERMANOVA (main test and pairwise tests) testing the differences between $\Delta \delta^{15} \mathrm{~N}$ of the macroalgae incubated in the three transects (T1, T2, T3) of the experimental sites (C1: Control 1; C2: Control 2; TS: Tourist site) of Rhodes in August 2018 and 2019. Data of the 2018 campaign were taken from Signa et al. (2020).

\begin{tabular}{cccccccc}
\hline $\begin{array}{c}\text { PERMANOVA } \\
\text { Main test }\end{array}$ & Source of variation & df & MS & Pseudo-F & P(perm) & Perms & Pair-wise tests \\
\hline Year & 1 & 18.95 & 106.14 & $\mathbf{0 . 0 0 1}$ & 997 & $2019<2018$ \\
Site & 2 & 0.29 & 1.64 & 0.204 & 997 & \\
Transect & 2 & 0.12 & 0.65 & 0.500 & 999 & \\
$\mathbf{\Delta} \boldsymbol{\delta}^{\mathbf{1 5}} \mathbf{N}(\mathbf{\%})$ & Year x Site & 2 & 0.16 & 0.89 & 0.414 & 999 & $\mathrm{~T} 1: \mathrm{C} 2<\mathrm{TS} ;$ \\
& Year x Transect & 2 & 0.10 & 0.57 & 0.580 & 999 & $\mathrm{TS}: \mathrm{T} 3<\mathrm{T} 1, \mathrm{C} 2: \mathrm{T} 2<\mathrm{T} 3$ \\
& Site x Transect & 4 & 0.50 & 2.83 & $\mathbf{0 . 0 2 7}$ & 998 & \\
& & & & & & & \\
\end{tabular}
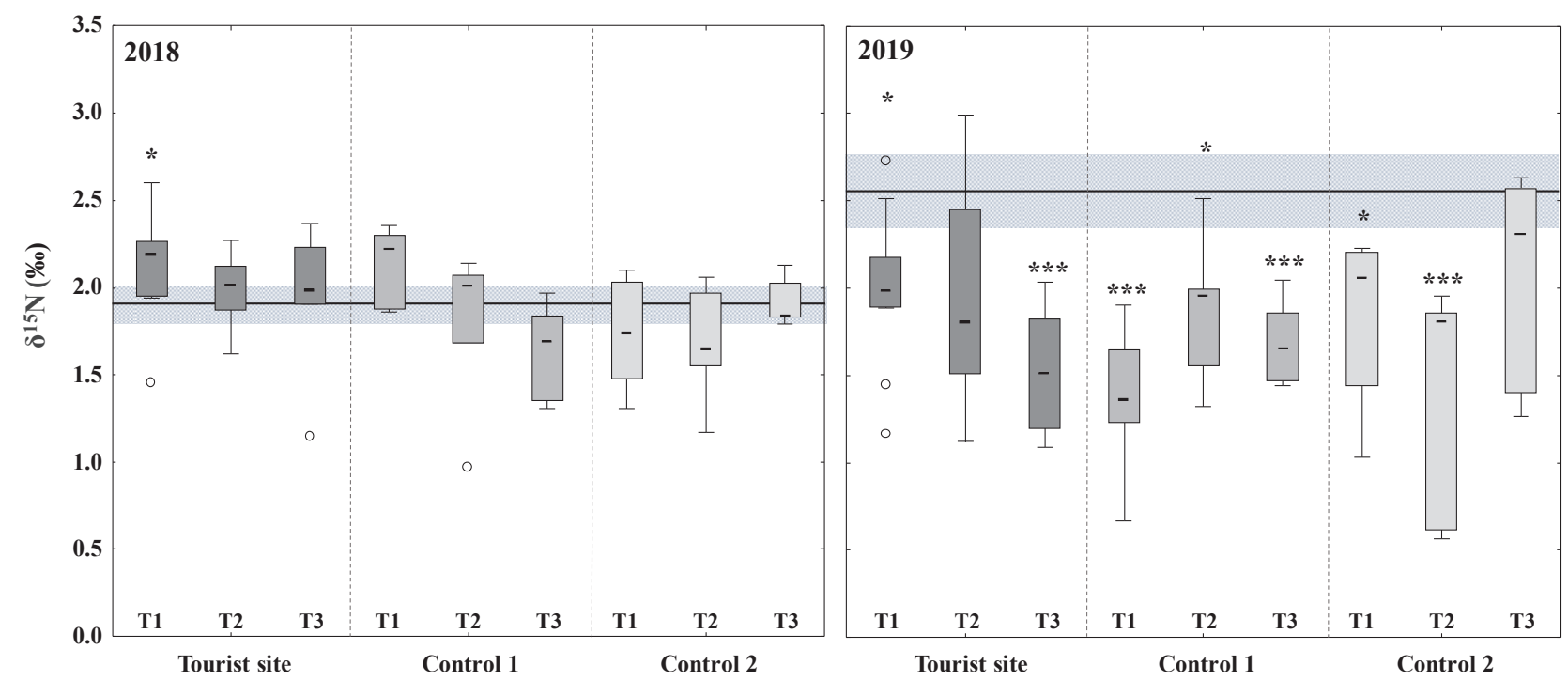

Fig. 4. Boxplot of $\delta^{15} \mathrm{~N}$ values of Cystoseira compressa deployed along the three transects at different distance from the coastline (T1: 100, T2: 200, T3: $300 \mathrm{~m}$ ) in the experimental sites of Rhodes in August 2018 and 2019. Boxes contain 50\% of the data, while whiskers represent the first and fourth quartiles. The horizontal marks within boxes indicate the median values, while circles outside the boxes represent outliers of the distribution. Asterisks over the boxes indicate the significance level of the differences between the $\delta^{15} \mathrm{~N}$ signature of the deployed macroalgae and that of the baseline, according to t-test. $\mathrm{p}$-values: $*=\mathrm{p}$-value $<0.05$, $* *=\mathrm{p}$-value $<0.01, * * *=\mathrm{p}$-value $<0.001$. The grey area overlaying the graphs indicates the mean and the standard deviation of the baseline. Data of the 2018 campaign were taken from Signa et al. (2020). 
jority of data recorded in the 2019 monitoring campaign was negative in all sites, while, most $\Delta \delta^{15} \mathrm{~N}$ data recorded in 2018 were comprised between 0 and $0.5 \%$ in the whole Tourist site and in the first transect of the Control 1, and were slightly negative elsewhere (Fig. 5).

\section{Discussion}

The biomonitoring activities carried out using macroalgae transplantation techniques did not reveal a marked occurrence of anthropogenic nutrients in coastal seawater of the Island of Rhodes. This overall result matched that obtained in 2018 by using the same methodological approach and reported by Signa et al. (2020), where, however, a slightly higher ${ }^{15} \mathrm{~N}$-enrichement was detected in the macroalgae transplanted in the Tourist site.

The active biomonitoring approach based on relocation of macroalgae between sites at different anthropic pressure is acknowledged as particularly useful for environmental management, as it gives time-integrated information about water nutrient enrichment and pollution even at short temporal scales (Costanzo et al., 2005; Huntington and Boyer, 2008; Rossi et al., 2018). The strength of this approach lies in the reliability of macroalgae as bioindicators of water pollution, and of nitrogen stable isotopes $\left(\delta^{15} \mathrm{~N}\right)$ as a proxy for anthropogenic nutrient occurrence (García-Seoane et al., 2018 and references therein). This is the reason why the analysis of the spatial and temporal patterns of isotopic variation of transplanted macroalgae, starting from the pivotal study of Costanzo et al. (2001), has been increasingly used to detect and map nutrient input plumes due to urban or industrial sewage discharges (Costanzo et al., 2005; Dailer et al., 2010; Deutsch and Voss, 2006; Orlandi et al., 2014). However, to our knowledge, the implementation of such approach to detect the major sources of nitrogen (marine vs. anthropogenic) in touristic coastal areas, has never been realized before the BLUEISLANDS project (see also Signa et al. 2020).

Here, the spatial patterns of the isotopic variation (i.e. $\Delta \delta^{15} \mathrm{~N}$ ) recorded by the macroalgae transplanted in Rhodes in August 2019 showed a low isotopic variation at all sites, which indicates overall good environmental conditions and rules out a marked input of tourism-driven
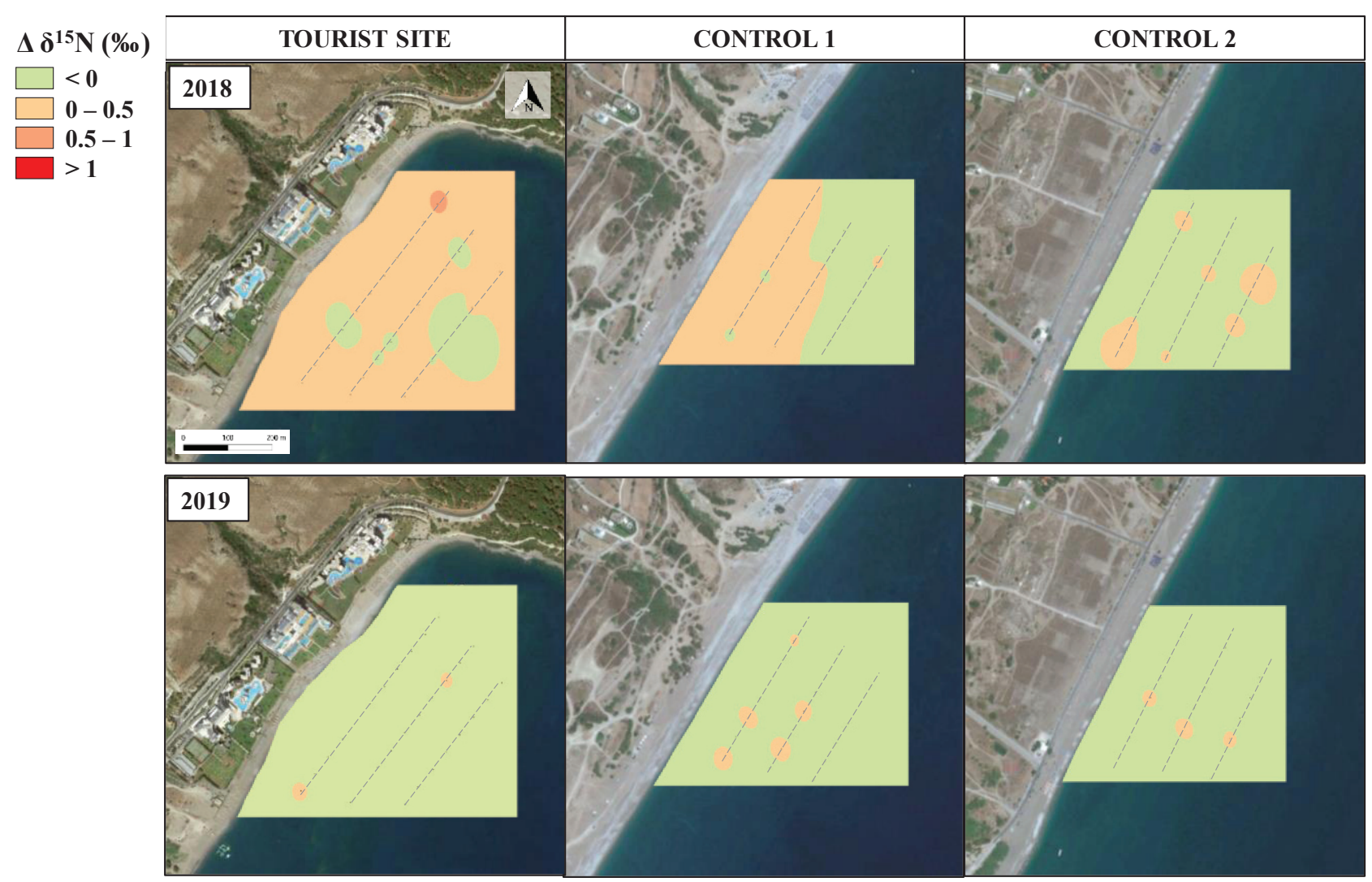

Fig. 5. Georeferenced maps of $\Delta \delta^{15} \mathrm{~N}$ values in August 2018 and 2019 at the experimental sites of Rhodes. Dashed lines indicate the three transects at increasing distance from the coastline (T1: 100, T2: 200 and T3: $300 \mathrm{~m}$ ) where macroalgae were incubated. Maps of the 2018 campaign were taken from Signa et al. (2020). 
anthropogenic nutrients potentially threatening the functioning of marine ecosystems. This outcome corroborates the results of the 2018 campaign, where, however, $\Delta \delta^{15} \mathrm{~N}$ values were significantly higher than those recorded in the following year. In more detail, most $\Delta \delta^{15} \mathrm{~N}$ values $(65 \%)$ in the macroalgae transplanted in August 2019 fell in the range comprised between -1.0 and $0.5 \%$, while, most $\Delta$ $\delta^{15} \mathrm{~N}$ values $(87 \%)$ for the 2018 campaign fell in the range from -0.5 to $0.5 \%$. Although this slight interannual variability, the low level of the isotopic variation in macroalgae in both years is likely attributable to natural variations and suggests negligible levels of anthropic-derived nitrogen. More than double isotopic enrichment (max value: $+1.8 \%$ ) was found, indeed, in macroalgae of the same genus (i.e. the species Cystoseira amentacea) transplanted for only two days in a Mediterranean coastal area affected by strong urbanization and abundant anthropogenic inputs (Orlandi et al., 2014).

Sewage discharge is characterized, indeed, by high concentrations of $\mathrm{NH}_{4}^{+}$and $\mathrm{NO}_{3}$, whose isotopic signature is typically highly ${ }^{15} \mathrm{~N}$-enriched compared with that of nitrogen nutrients of marine origin (Lapointe et al., 2005), due to denitrification and ammonium volatilization processes that occur during sewage treatment stages (Alquezar et al., 2013; Lapointe et al., 2005; Viana et al., 2011). Accordingly, sewage effluents, including secondary treated wastewater discharges from sewage outfalls, as well as septic tank effluents, like those that could potentially arise from beach resorts and kiosks of the Tourist site, are expected to have a $\delta^{15} \mathrm{~N}$ range from $7 \%$ o to $38 \%$ depending on the level and type of treatment (reviewed by Dailer et al., 2010). $\delta^{15} \mathrm{~N}$ of sewage particulate organic matter (SPOM) collected from the wastewater treatment plant of Rhodes fell into this range, and showed also a significantly higher nitrogen content than that of the experimental sites. In contrast, $\delta^{15} \mathrm{~N}$ and nitrogen content of coastal SPOM from all the study sites were significantly lower, suggesting a negligible occurrence of anthropogenic nutrients. At the same time, macroalgae that rely on sewage-derived nitrogen nutrients are ${ }^{15} \mathrm{~N}$-enriched over a range from +3 to $+16 \%$ (Costanzo et al., 2005; Lapointe et al., 2005), while transplanted macroalgae in all study sites showed ${ }^{15} \mathrm{~N}$-depleted values, close to those of macroalgae from the pristine collection site.

On the other hand, the overall negative $\delta^{15} \mathrm{~N}$ values are not even attributable to the occurrence of fertilizers through runoff. Although fertilizer nitrogen sources have low $\delta^{15} \mathrm{~N}$ values, ranging from -4 to $+4 \%$ (Dailer et al., 2010), there are no agricultural fields in the study area and there was not rainfall in the period before the experiment, dismissing the possibility that transplanted macroalgae may have been influenced by agricultural runoff.

Moreover, the close year-to-year values of temperature and salinity rules out any influence of these environmental variables on the observed $\delta^{15} \mathrm{~N}$ of macroalgae, also be- cause Cystoseira compressa, being a upper-shore species is eco-physiologically adapted to resist high environmental stress and variability (Betancor et al., 2015; Delgado et al., 1995).

Overall, the outcomes of the 2019 monitoring campaign confirmed those of the 2018 campaign and suggest a negligible occurrence of anthropic-derived nutrients in the coastal seawater at Rhodes, as the variation of $\delta^{15} \mathrm{~N}$ in most cases was minor and in the range $-1 \%$ - $+0.5 \%$. These results indicate overall good environmental conditions and are further corroborated by the routine monitoring programs carried out through the analysis of microbial indicators (Escherichia coli and intestinal enterococci) (EEA, 2019, 2018) in accordance with the European "Bathing Water Directive" (2006/7/EC). This confirms the effectiveness of the methodological approach used in this study and reflects the success of local environmental policies implemented in the last decades (Economides and Arvanitides, 1989) aiming at protecting the environment and increasing competitiveness in the offered tourist services at Rhodes (Tselentis et al., 2006). Nevertheless, it should be noted that, although the outcomes match, the objectives of the two approaches are ultimately different. The routine monitoring of fecal indicators is intended to ensure the safety of water bodies for human recreation (Korajkic et al., 2018), while the biomonitoring approach used here aims at assessing the environmental quality of coastal seawater and can be intended to ensure the safety of the ecosystem functions. Indeed, changes in the relative abundance of nitrogen stable isotopes can be detected before coastal systems undergo alterations in structure and function (Viana et al., 2011) and offers many other advantages compared to traditional methods for environmental monitoring. In particular, traditional monitoring methods, by the analysis of only nutrients and phytoplankton biomass, provide only an instantaneous view of nutrient dispersal, as the signal of these tracers is rapidly lost in well-mixed waters (Gartner et al., 2002). In contrast, biomonitoring by the analysis of $\delta^{15} \mathrm{~N}$ of transplanted macroalgae provides a space- and time-integrated information about anthropogenic nutrient dispersal, allowing to detect episodic nutrient pulses that otherwise might be missed.

\section{Conclusion}

The biomonitoring approach used in this study, based on the analysis of the spatial patterns of $\delta^{15} \mathrm{~N}$ of transplanted macroalgae, showed that tourist activities in Rhodes (Greece) do not cause evident input of anthropic-derived nutrients in coastal seawater, suggesting that management of wastewater and sewage disposal is efficient despite the summer tourist peak. This study confirms that the adopted approach, by combining transplanting and isotopic 
techniques, is a rapid and reliable tool for detecting and mapping anthropogenic nutrient dispersal even in wellmixed oligotrophic tourist waters and at short temporal scales. In addition, the spatial patterns of isotopic data were used to produce maps, which are easily readable tools that can support the development of monitoring plan and the implementation of actions aimed at ameliorating the environmental conditions. The early assessment of the occurrence of anthropic nutrients is crucial, indeed, for policy- and decision-makers, to avoid marine ecosystem deterioration, promote actions to foster ecosystem quality and sustainable tourism with beneficial repercussions on tourism itself.

\section{Acknowledgements}

This study was funded by the Interreg MED BLUEISLANDS project (Seasonal variation of waste as effect of tourism. Ref: 613 / 1MED15_3.1_M12_273). We are grateful to all the people who gave us their support to carry out the experiments in Rhodes, in particular the local project partner, namely the Municipality of Rhodes (especially in the person of the Mayor Advisor on Water Resources and Environmental Management Dr. Christos C. Gamvroudis). We are also grateful to all the LaBioMar (University of Palermo) staff, and, in particular, to Adele Elisa Aleo, Federica Cassetti, Laura Ciriminna, Veronica Santinelli, Andrea Savona, and Cecilia Tramati for their field and laboratory support.

\section{References}

2000/60/EC, 2000. Directive 2000/60/EC of the European Parliament and of the Council of 23 October 2000 establishing a framework for Community action in the field of water policy. Off. J. Eur. Union L 327, 1-73.

2006/7/EC, 2006. Directive 2006/7/EC of the European Parliament and of the Council of 15 February 2006 concerning the management of bathing water quality and repealing Directive 76/160/EEC. Off. J. Eur. Union L 064, 37-51.

Abaya, L.M., Wiegner, T.N., Beets, J.P., Colbert, S.L., Carlson, K.M., Kramer, K.L., 2018. Spatial distribution of sewage pollution on a Hawaiian coral reef. Mar. Pollut. Bull. 130, 335-347.

Alquezar, R., Glendenning, L., Costanzo, S., 2013. The use of the brown macroalgae, Sargassum flavicans, as a potential bioindicator of industrial nutrient enrichment. Mar. Pollut. Bull. 77, 140-146. doi:10.1016/j. marpolbul.2013.10.013

Anderson, L.G., Rocliffe, S., Haddaway, N.R., Dunn, A.M., 2015. The role of tourism and recreation in the spread of non-native species: A systematic review and meta-analysis. PLoS One 10, 1-15. doi:10.1371/journal.pone.0140833

Bellan, G.L., Bellan-Santini, D.R., 2001. A review of littoral tourism, sport and leisure activities: Consequences on marine flora and fauna. Aquat. Conserv. Mar. Freshw. Ecosyst. 11, 325-333. doi:10.1002/aqc.461

Betancor, S., Domínguez, B., Tuya, F., Figueroa, F.L., Haroun, R., 2015. Photosynthetic performance and photoprotection of Cystoseira humilis (Phaeophyceae) and Digenea simplex (Rhodophyceae) in an intertidal rock pool. Aquat. Bot. 121, 16-25.

Cole, M.L., Kroeger, K.D., McClelland, J.W., Valiela, I., 2005. Macrophytes as indicators of land-derived wastewater: Application of a $\delta^{15} \mathrm{~N}$ method in aquatic systems. Water Resour. Res. 41, 1-9. doi:10.1029/2004WR003269

Costanzo, S.D., O’Donohue, M.J., Dennison, W.C., Loneragan, N.R., Thomas, M., 2001. A new approach for detecting and mapping sewage impacts. Mar. Pollut. Bull. 42, 149-156. doi:10.1016/S0025-326X(00)00125-9

Costanzo, S.D., Udy, J., Longstaff, B., Jones, A., 2005. Using nitrogen stable isotope ratios $\left(\delta^{15} \mathrm{~N}\right)$ of macroalgae to determine the effectiveness of sewage upgrades: Changes in the extent of sewage plumes over four years in Moreton Bay, Australia. Mar. Pollut. Bull. 51, 212217. doi:10.1016/j.marpolbul.2004.10.018

Dailer, M.L., Knox, R.S., Smith, J.E., Napier, M., Smith, C.M., 2010. Using $\delta^{15} \mathrm{~N}$ values in algal tissue to map locations and potential sources of anthropogenic nutrient inputs on the island of Maui, Hawai'i, USA. Mar. Pollut. Bull. 60, 655-671. doi:10.1016/j.marpolbul.2009.12.021

Davenport, J., Davenport, J.L., 2006. The impact of tourism and personal leisure transport on coastal environments: A review. Estuar. Coast. Shelf Sci. 67, 280-292. doi:10.1016/j.ecss.2005.11.026

Delgado, O., Rodriguez-Prieto, C., Frigola-Gironés, L., Ballesteros, E., 1995. Drought Tolerance and Light Requirements of High and Low Sublittoral Species of Mediterranean Macroalgae of the Genus Cystoseira C. Agardh (Fucales, Phaeophyceae). Bot. Mar. 38, 127132.

Deutsch, B., Voss, M., 2006. Anthropogenic nitrogen input traced by means of $\delta^{15} \mathrm{~N}$ values in macroalgae: Results from in-situ incubation experiments. Sci. Total Environ. 366, 799-808. doi:10.1016/j.scitotenv.2005.10.013

Drius, M., Bongiorni, L., Depellegrin, D., Menegon, S., Pugnetti, A., Stifter, S., 2019. Tackling challenges for Mediterranean sustainable coastal tourism: An ecosystem service perspective. Sci. Total Environ. 652, 13021317. doi:10.1016/j.scitotenv.2018.10.121

Economides, D.J., Arvanitides, G., 1989. Sea water quality monitoring in Rhodes and Cos (Greece). Toxicol. Environ. Chem. 20-21, 383-386. 
Economou, A., 2007. The influence of tourist development in the coastal natural environment of Faliraki on the island of Rhodes. Real Corp 007 Proc. 007, 159-165.

EEA, 2019. Greek bathing water quality in 2018. Eur. Environ. Agency 1-9.

EEA, 2018. Greek bathing water quality in 2017. Eur. Environ. Agency 1-9.

Fernandes, M., Benger, S., Sharma, S.K., Gaylard, S., Kildea, T., Hoare, S., Braley, M., Irving, A.D., 2012. The use of $\delta^{15} \mathrm{~N}$ signatures of translocated macroalgae to map coastal nutrient plumes: improving species selection and spatial analysis of metropolitan datasets. J. Environ. Monit. 14, 2399-2410. doi:10.1039/ c2em10997b

García-Sanz, T., Ruiz, J.M., Pérez, M., Ruiz, M., 2011. Assessment of dissolved nutrients dispersal derived from offshore fish-farm using nitrogen stable isotope ratios $\left(\delta^{15} \mathrm{~N}\right)$ in macroalgal bioassays. Estuar. Coast. Shelf Sci. 91, 361-370. doi:10.1016/j.ecss.2010.10.025

García-Seoane, R., Fernández, J.A., Villares, R., Aboal, J.R., 2018. Use of macroalgae to biomonitor pollutants in coastal waters: Optimization of the methodology. Ecol. Indic. 84, 710-726.

Gartner, A., Lavery, P., Smit, A.J., 2002. Use of $\delta^{15} \mathrm{~N}$ signatures of different functional forms of macroalgae and filter-feeders to reveal temporal and spatial patterns in sewage dispersal. Mar. Ecol. Prog. Ser. 235, 63-73.

Gössling, S., 2002. Global environmental consequences of tourism. Glob. Environ. Chang. 12, 283-302.

Gröcke, D.R., Racionero-Gómez, B., Marschalek, J.W., Greenwell, H.C., 2017. Translocation of isotopically distinct macroalgae: A route to low-cost biomonitoring? Chemosphere 184, 1175-1185. doi:10.1016/j.chemosphere.2017.06.082

Hall, C.M., 2001. Trends in ocean and coastal tourism: The end of the last frontier? Ocean Coast. Manag. 44, 601-618. doi:10.1016/S0964-5691(01)00071-0

Huntington, B.E., Boyer, K.E., 2008. Evaluating patterns of nitrogen supply using macroalgal tissue content and stable isotopic signatures in Tomales Bay, CA. Environ. Bioindic. 3, 180-192. doi:10.1080/15555270802537510

Keeler, B.L., Polasky, S., Brauman, K.A., Johnson, K.A., Finlay, J.C., O’Neille, A., Kovacs, K., Dalzell, B., 2012. Linking water quality and well-being for improved assessment and valuation of ecosystem services. Proc. Natl. Acad. Sci. U. S. A. 109, 18619-18624.

Korajkic, A., McMinn, B.R., Harwood, V.J., 2018. Relationships between microbial indicators and pathogens in recreational water settings. Int. J. Environ. Res. Public Health 15, 1-39.

Kyriakou, K., Hatiris, G.A., Kapsımalıs, V., Sourıanos, E., Vandarak1s, D., 2017. The application of GIS in Tourism Carrying Capacity Assessment for the Island of
Rhodes, Greece, in: 15th International Conference on Environmental Science and Technology.

Lapointe, B.E., Barile, P.J., Littler, M.M., Littler, D.S., 2005. Macroalgal blooms on southeast Florida coral reefs II . Cross-shelf discrimination of nitrogen sources indicates widespread assimilation of sewage nitrogen. Harmful Algae 4, 1106-1122.

Mwaura, J., Umezawa, Y., Nakamura, T., Kamau, J., 2017. Evidence of chronic anthropogenic nutrient within coastal lagoon reefs adjacent to urban and tourism centers, Kenya: A stable isotope approach. Mar. Pollut. Bull. 119, 74-86. doi:10.1016/j.marpolbul.2017.04.028 Orlandi, L., Bentivoglio, F., Carlino, P., Calizza, E., Rossi, D., Costantini, M.L., Rossi, L., 2014. $\delta^{15} \mathrm{~N}$ variation in Ulva lactuca as a proxy for anthropogenic nitrogen inputs in coastal areas of Gulf of Gaeta (Mediterranean Sea). Mar. Pollut. Bull. 84, 76-82. doi:10.1016/j.marpolbul.2014.05.036

Pappas, N. V., 2008. City of Rhodes: Residents' attitudes toward tourism impacts and development. Anatolia 19, 51-70. doi:10.1080/13032917.2008.9687053

Philip, G.M., Watson, D.F., 1982. A precise method for determining contoured surfaces. APPEA J. 22, 205-212.

Rossi, L., Calizza, E., Careddu, G., Rossi, D., Orlandi, L., Jona-Lasinio, G., Aguzzi, L., Costantini, M.L., 2018. Space-time monitoring of coastal pollution in the Gulf of Gaeta, Italy, using $\Delta^{15} \mathrm{~N}$ values of Ulva lactuca, landscape hydromorphology, and Bayesian Kriging modelling. Mar. Pollut. Bull. 126, 479-487.

Signa, G., Andolina, C., Tomasello, A., Mazzola, A., Vizzini, S., 2020. $\delta^{15} \mathrm{~N}$ in deployed macroalgae as a tool to monitor nutrient input driven by tourism activities in Mediterranean islands. Mar. Pollut. Bull. 111504

Signa, G., Di Leonardo, R., Vaccaro, A., Tramati, C.D., Mazzola, A., Vizzini, S., 2015. Lipid and fatty acid biomarkers as proxies for environmental contamination in caged mussels Mytilus galloprovincialis. Ecol. Indic. 57, 384-394.

Signa, G., Mazzola, A., Vizzini, S., 2012. Effects of a sml seagull colony on trophic status and primary production in a Mediterranean coastal system (Marinello ponds, Italy). Estuar. Coast. Shelf Sci. 111, 27-34. doi:10.1016/j. ecss.2012.06.008

Theocharis, A., Balopoulos, E., Kioroglou, S., Kontoyiannis, H., Iona, A., 1999. A synthesis of the circulation and hydrography of the South Aegean Sea and the Straits of the Cretan Arc (March 1994-January 1995). Prog. Oceanogr. doi:10.1016/S0079-6611(99)00041-5

Tselentis, B.S., Prokopiou, D.G., Toanoglou, M., 2006. Carrying capacity assessment for the Greek islands of Kalymnos, Kos and Rhodes. WIT Trans. Ecol. Environ. 97, 353-363.

Tsiamis, K., Panayotidis, P., Montesanto, B., 2007. Contribution To the Study of the Marine Vegetation of Rhodes 
Island ( Greece ). Proc. Third Mediterr. Symp. Mar. Veg. 7.

Viana, I.G., Bode, A., 2013. Stable nitrogen isotopes in coastal macroalgae: Geographic and anthropogenic variability. Sci. Total Environ. 443, 887-895. doi:10.1016/j.scitotenv.2012.11.065

Viana, I.G., Fernández, J.A., Aboal, J.R., Carballeira, A., 2011. Measurement of $\delta^{15} \mathrm{~N}$ in macroalgae stored in an environmental specimen bank for regional scale monitoring of eutrophication in coastal areas. Ecol. Indic. 11, 888-895.

Watson, D.F., Philip, G.M., 1985. A refinement of inverse ditance weighted interpolation. Geoprocessing 2, 315327.

World Tourism Organization, 2019. International Tourism Highlights, 2019 Edition, UNWTO. Madrid, Spain. 